\title{
$\checkmark$ Injury prevention in paediatric sport-related injuries: a scientific approach
}

\section{A Emery ${ }^{1,2,3}$}

Youth have very high participation rates in sport, and sport is the leading cause of youth injury in many countries. ${ }^{1-7}$ Canadian studies report that $30-40 \%$ of youth (ages 11-18 years) seek medical attention for a sport injury annually. ${ }^{2}$ While physical activity prevents all-cause morbidity associated with a sedentary lifestyle, injuries can become a barrier to physical activity. Injury prevention in youth is a critical issue in healthcare and in the promotion of health and wellness in our communities, and is becoming a public health priority. ${ }^{8-9}$ However, there is a discrepancy between the amount of research in this area and the public health burden of injury in youth sport where injuries are often predictable and preventable. ${ }^{10}$ An interdisciplinary and rigorous scientific approach is critical to understanding the complexity of injury risks, prevention and safety policies related to sport injury in youth.

Studies that examine prevention strategies are paramount in establishing best practices for prevention in youth sport for healthcare practitioners, sport and health administrators, policy makers, athletes, coaches, parents and the public. The results of research in this area are often pivotal in decisions made to continue, discontinue, allocate or reduce funds from given public health, sport and healthcare programmes. As such, a rigorous methodological approach to research in injury prevention in youth sport is essential to inform practice and policy most appropriately. The purpose of this paper is to advocate for a scientific approach to research in injury prevention in child and adolescent sport.

\footnotetext{
${ }^{1}$ Sport Medicine Centre, Roger Jackson Centre for Health and Wellness Research, Faculty of Kinesiology, University of Calgary, Calgary, Canada; ${ }^{2}$ Alberta Children's Hospital Research Institute for Child and Maternal Health, Department of Pediatrics, Faculty of Medicine, University of Calgary, Calgary, Canada; ${ }^{3}$ Department of Community Health Sciences, Faculty of Medicine, University of Calgary, Calgary, Canada

Correspondence to: Dr C A Emery, Sport Medicine Centre, University of Calgary, 2500 University Drive NW, Calgary, Alberta, Canada T2N 1N4; caemery@ucalgary.ca
}

\section{FRAMEWORK FOR INJURY-PREVENTION RESEARCH}

Sixty years ago, Gordon ${ }^{11}$ established the use of epidemiological principles often used to study infectious diseases, to examine injury and relate it to host, agent, and environmental factors. Gibson ${ }^{12}$ built on this concept by identifying the agent of injury as physical energy (ie, mechanical, thermal, chemical or electrical) and further examining the reduction in tissue damaging transfer of physical energy to the human body. Haddon $^{13}$ extended this notion through the construction of a two-dimensional matrix describing injury countermeasures. The first axis relates to temporality (ie, pre-event, event and postevent.) ${ }^{13}$ The second axis describes risk factors that may affect the likelihood or severity of injury (ie, host or human factors, agent factors including equipment, physical and social environmental conditions)..$^{13}$ Through Haddon's interest in motor vehicle collision, he recommended a shift in focus from crash prevention to proper protection of the body through increasing the focus on agent and physical environmental factors in order to prevent injury. ${ }^{13}$

Runyan ${ }^{14}$ suggested another dimension to Haddon's matrix which included policyrelated factors (ie, intervention effectiveness, cost, freedom, equity, stigmatisation, preferences of the affected community or individuals) which would further influence the selection of a specific injury prevention strategy. Ongoing consideration of this dimension will continue to influence the development of further research in injury prevention in youth sport.

More recent literature highlights the importance of considering how factors interact to influence risk of injury. ${ }^{3}{ }^{15}{ }^{16}$ van Mechelen et $a l^{17}$ described the research process in four steps: (1) establishing the extent of the injury, (2) establishing the aetiology of injury, (3) introducing a preventive measure and (4) assessing its effectiveness by repeating step 1 . Finch ${ }^{18}$ further proposed a new framework "Translating Research into Injury Prevention" (TRIPP). Finch further proposes TRIPP stage 5 in which the intervention context is established to inform implementation strategies and TRIPP stage 6 in which the effectiveness of preventive measures are evaluated in the implementation context. ${ }^{18}$ Finch highlights translating research into the real-world context considering the current safety practices, motivations/barriers to uptake and player behaviours and sporting culture.

Meeuwisse $^{19}$ established the sport injury event along a continuum in which there exists a complex interaction between intrinsic risk factors (eg, age, strength, previous injury) and exposure to extrinsic risk factors (eg, field conditions, equipment) that affect susceptibility to injury. An inciting event will ultimately produce an injury in a susceptible sport participant. ${ }^{19}$ Bahr and Krosshaug ${ }^{20}$ built on this model to highlight the mechanism of injury including biomechanical components, the playing situation and player/ opponent behaviour. Meeuwisse et $a^{21}$ build further on this model in light of limitations with the implicit linear paradigm (fig 1). The approach often used in injury prevention studies involves following individuals, exposed to some risk factor(s) and/or intervention over time, to measure the outcome of injury. Meeuwisse et $a^{21}$ argue that exposure is a combination of having a risk factor and then participating with it. A participant may be exposed to the same or different risk factors repeatedly through multiple participations, and injuries may or may not occur under similar conditions. ${ }^{21}$ In addition, injury does not permanently remove an individual from participation and, therefore, may not represent a finite endpoint. ${ }^{21}$ Gissane et a ${ }^{22}$ also previously stated that a linear model does not account for what happens after injury. Gissane et $a l^{22}$ developed a cyclical model for the investigation of contact sports to account for the return of healthy players to sport. It was recognised that injured athletes could return to a lower level of sport, but their approach may not permit these players to return to the same cycle of exposure. ${ }^{22}$ What was not emphasised, prior to Meeuwisse et al's $\mathrm{s}^{21}$ development of a dynamic recursive model, was the notion that there may also be recurrent changes in susceptibility to injury in the course of sports participation with no injury. These inciting "exposures" or "events" may not result in injury but can produce adaptation and continually change risk. ${ }^{21}$ Meeuwisse et $a^{21}$ highlight that an initial set of risk factors preceding an injury are not necessarily stable over time. Ongoing participation may produce 
adaptation, maladaptation, injury or complete/incomplete recovery from injury. ${ }^{21}$ This should be a key consideration in designing and interpreting research in injury prevention in youth sport.

\section{SHIFTING THE FOCUS TO EVALUATION}

A substantial body of literature has examined injury burden and risk factors for injury in youth sport. ${ }^{3617}$ Much of this literature focuses on injury "surveillance, " a term broadly and often incorrectly used in the literature. Pless ${ }^{23}$ clearly identifies the difference between surveys, surveillance and registries. Surveys are one-off, episodic or repeated at regular intervals. ${ }^{23}$ They are used to collect detailed data, though clearly at risk of recall bias related to self-report..$^{23}$ Registries are the file of data concerning all cases of a particular disease, in a defined population, such that the cases can be related to a population base. ${ }^{24}$ Injury surveillance is the collection of data on who, when, where and sometimes how people become injured..$^{25}$ The purpose of injury surveillance is to monitor trends and target injury control measures which could lead to substantial reductions if implemented. Pless $^{23}$ argues that while a great deal of resources are often spent on developing better surveillance systems, these are not often tied to preventive interventions. Finch $^{26}$ argues that in raising the profile of sports injury, adequate surveillance is a necessary but not sufficient precursor to preventive efforts. I would further suggest that rigorous methodology associated with surveillance continue to be of upmost

importance in the appropriate evaluation of prevention strategies. It is only with rigorous scientific evaluation that efficient and appropriate translation will occur in the community.

\section{METHODOLOGICAL CONSIDERATIONS Research question}

Identifying the problem to be addressed and the appropriate research question is critical to the design of any study evaluating an injury-prevention strategy in youth sport. An initial problem statement may be: "The public health burden of injuries in youth soccer is significant." 727 A critical review of the literature examining the effectiveness of injury prevention programmes in soccer players is essential in identifying the gaps in knowledge and methodological considerations before identifying the primary research questions and design. For example, Emery and Meeuwisse ${ }^{28}$ identified a primary research question as follows: "What is the effectiveness of a teambased neuromuscular training programme in reducing injury rates in youth soccer players?" Secondary research questions included: "What is the cost-effectiveness of a neuromuscular training programme in youth soccer players?" and "Is there a dose-response effect based on the reported adherence to a neuromuscular training programme in youth soccer players?" Such questions were addressed in other youth injury-prevention studies. ${ }^{29}{ }^{30}$

Delineation of efficacy versus effectiveness in examining the effectiveness of a prevention strategy in youth sport is
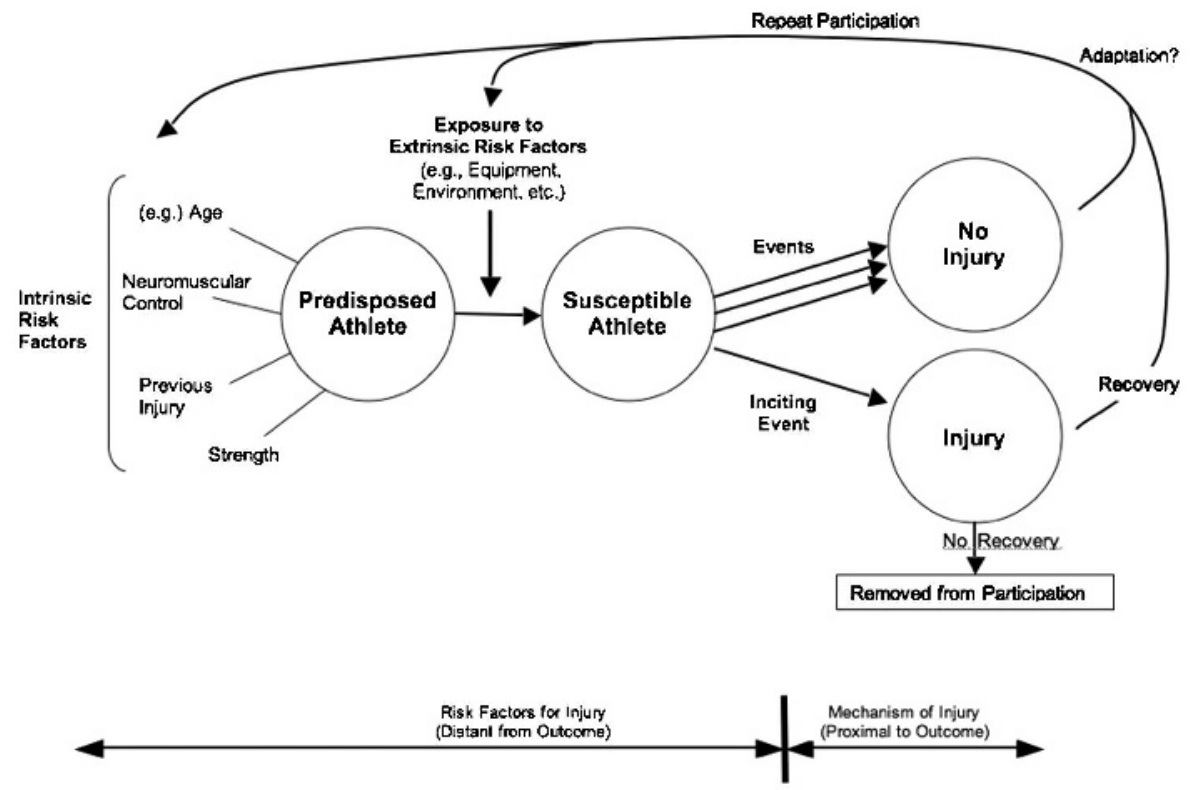

Figure 1 Dynamic, recursive model of aetiology in sport injury (reproduced with permission from Meeuwisse et $a^{21}$ ). important. Efficacy refers to the benefit of an intervention under controlled and ideally randomised conditions. $^{31}$ Effectiveness refers to the benefit of an intervention under "real world" conditions. ${ }^{31}$ Consideration of the feasibility and potential uptake of community interventions under "real-world" conditions is critical to "real-world" prevention gains. ${ }^{18}$ Finch recommends that all injury prevention evaluation studies should include information on key implementation factors (eg, recruitment rates, biases, rate of uptake and barriers to uptake), and thus guidelines require development regarding the recording and reporting of implementation factors. ${ }^{18}$

\section{Research design}

In evaluating an injury-prevention intervention in youth sport, arguably the strongest form of evidence is a randomised controlled trial (RCT). ${ }^{32}$ Examples of RCTs in youth sport include studies examining interventions in handball, basketball, soccer, rugby and physical education programmes. ${ }^{28-30}{ }^{33-41}$ It is not always feasible or ethical to randomise participants in youth sport. Quasi-experimental designs have similarities to RCT designs though lack random assignment of subjects, a control group or both. ${ }^{31}$ Caine et $a^{12}$ provide a comprehensive review of epidemiology in youth sport which includes a summary of 12 non-RCTs and nine RCTs evaluating injury prevention strategies in a variety of youth sports. In examining sport-specific neuromuscular training prevention strategies, it may be increasingly difficult to rationalise a control group in light of the evidence currently available supporting the protective effects of such programmes. $2829343537-$ ${ }^{39}$ In many quasi-experimental designs (ie, pre-experimental, repeated measures) one cannot be certain that changes are independent of another factor (eg, time) rather than the intervention itself. ${ }^{31}$ Historical cohorts are sometimes used as the control group for comparison. ${ }^{43}$ Study groups, however, may differ on other factors than the intervention itself (eg, rules, coaches, team dynamics). Further, if the intervention to be examined is already in place, and a natural control group exists, an observational cohort study design may be the design of choice.

In quasi-experimental designs (ie, nonRCTs), it is possible to control for nonequivalence in the analysis phase if potential confounders (eg, age, previous injury history) are measured at baseline. The caution to interpreting the results of these studies is that subjects may 


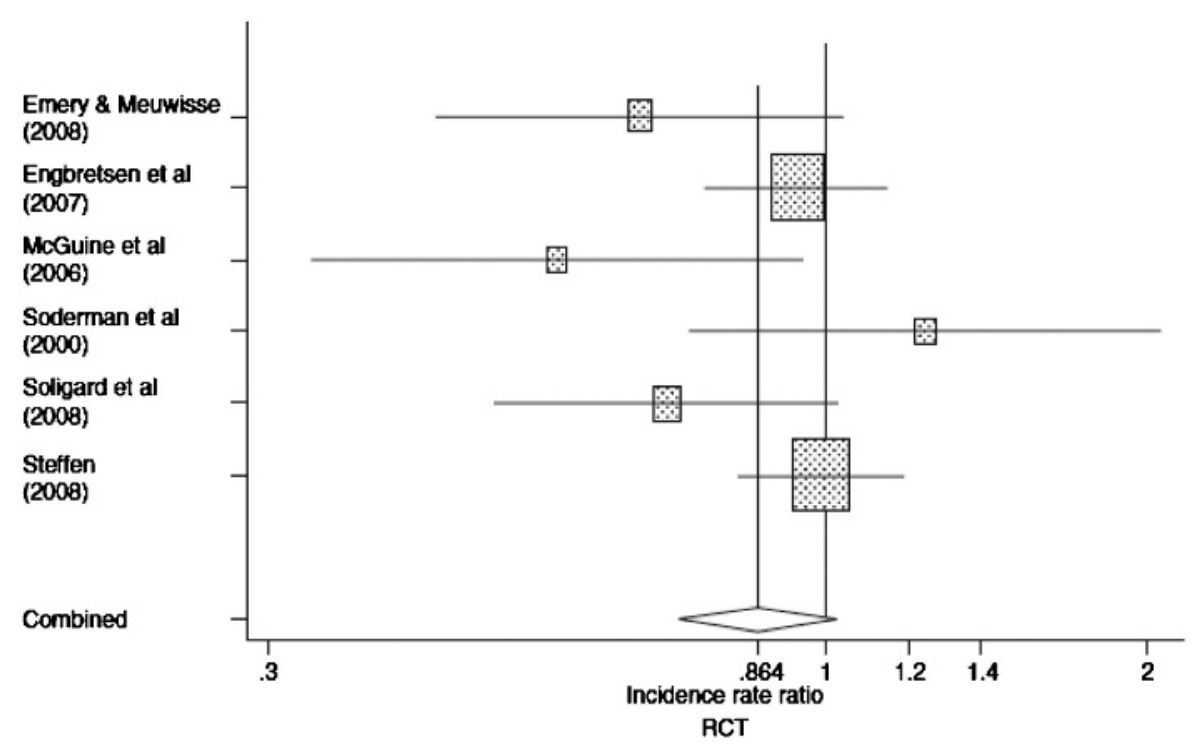

Figure 2 Randomised controlled trials (RCTs) examining lower-extremity neuromuscular injuryprevention strategies in soccer (reproduced with permission from Emery ${ }^{51}$ ).

self-select to study groups, or recruitment may be influenced by anticipated study group assignment, leading to selection bias. Evidence for selection bias in the overestimation of the preventive effect of neuromuscular training programmes in soccer can be described by combining the results of studies using RCT designs (fig 2) and non-RCT designs (fig 3). ${ }^{28} 34-3643-51$ An extension to studies including adult elite soccer players was required due to a paucity of youth studies. A meta-analysis was conducted to produce combined estimates of incidence rate ratios (IRR) based on a random effects model for six RCT (fig 2) and five non-RCT studies (fig 3). ${ }^{51}{ }^{52}$ All analyses were conducted in Intercooled Stata $10 .^{53}$ The size of the box in these figures represents the relative weights given to each based on the standard errors of the IRR. The combined estimate for RCT studies examining a preventive effect of neuromuscular training in the reduction in lower extremity injuries in soccer is 0.86 (95\% CI 0.72 to 1.03) and for non-RCT studies examining the same is 0.33 (95\% CI 0.16 to 0.65$)$. The point estimates suggest a significantly greater protective effect in the non-RCT studies (67\% reduction in injury rate) compared with the RCT studies $\left(14 \%\right.$ reduction in injury rate)..$^{51}$ In addition, the $95 \%$ CIs for the combined estimates indicate this protective effect to be significant only in the combined non-RCT studies. In examining these figures, it is clear that the RCT studies provide estimates of effect that are smaller and not significant based on the $95 \%$ CIs which include IRR $=1.0$ in all but one study. ${ }^{50}$ As such, these combined estimates arguably provide some evidence for the use of an RCT design to minimise selection bias where both feasible and ethical. ${ }^{51}$

\section{Study participants}

The generalisability of results in a study examining an intervention in youth sport depends on clear delineation of the sampling frame (ie, inclusion and exclusion criteria), methods of sampling and availability of potential study participants. While pure random sampling is often ideal, stratified random sampling may also be employed to select a sample that reflects a similar distribution of study participants in the population (eg, based on gender, level of play). ${ }^{28} 29$ Cluster sampling may also be considered if individuals naturally exist in groups (ie, teams, families, clinics). ${ }^{32}$ Considering cluster in the design is paramount if contamination is a concern, if an intervention is introduced at a group level or if participants within a cluster are more similar than participants between clusters. There are significant methodological implications of clustering to consider in the study design and analysis. ${ }^{54} 55$ Implications of cluster design and analysis are discussed in detail elsewhere, but clear justification is critical given the lack of statistical efficiency compared with an individual level design with the same number of participants. ${ }^{51} 55$ Independent of methods of randomisation, allocation concealment is critical to minimise potential investigator bias. ${ }^{56}$ One must also be aware that participant drop-out may lead to selection bias, particularly if the reasons for drop-out are related to the study outcome, and/or drop-out rates are different between study groups.

Baseline comparability of study groups must be examined in any study evaluating the effectiveness of an intervention, regardless of randomisation, to establish the equivalence of study groups (ie, age, injury history). Baseline imbalances may be reduced by stratified randomisation or controlled for in the analysis. ${ }^{32}$ Meeuwisse et a ${ }^{21}$ also emphasise, however, that some of these risk factors are not stable over time. The design should include repeated follow-up measurements if baseline characteristics are expected to change over time (eg, strength, balance, fitness).

\section{Intervention}

Detailed reporting of an intervention should include components, method of delivery, length, time frame and definition of adherence. The comparison group may be a true control or receive an alternate intervention based on current standard of practice. $^{28} 2933$ However, any difference between study groups may not be attributed to the components of the intervention alone if there is no intervention introduced in the control group. Differences may be attributed to a Hawthorne effect related to changes in performance in the intervention group as a result of "being studied." 31 Participants and research personnel may also overcompensate with effort and delivery respectively, if they know they are participating in an alternative control programme. Blinding subjects to details of the alternative intervention may reduce this potential threat to validity. ${ }^{28} 2933$ An attempt should be made to have consistency between study groups with respect to delivery, expected adherence, length and time frame. ${ }^{28} 2933$

As pointed out by Finch, ${ }^{18}$ evaluation of key implementation factors (ie, recruitment rates, biases, rate of uptake and reasons for non-adherence) is critical in the interpretation of study results. Adherence may be based on self-report, observation and/or evaluation of a marker variable (ie, measurement of balance ability).$^{28-3033}$ If adherence is reported, this will allow for the potential evaluation of a dose-response effect. It is important to recognise both potential non-adherence and contamination between study groups. Blinding subjects to the specifics of the other study group intervention and cluster randomisation will help to minimise contamination. 


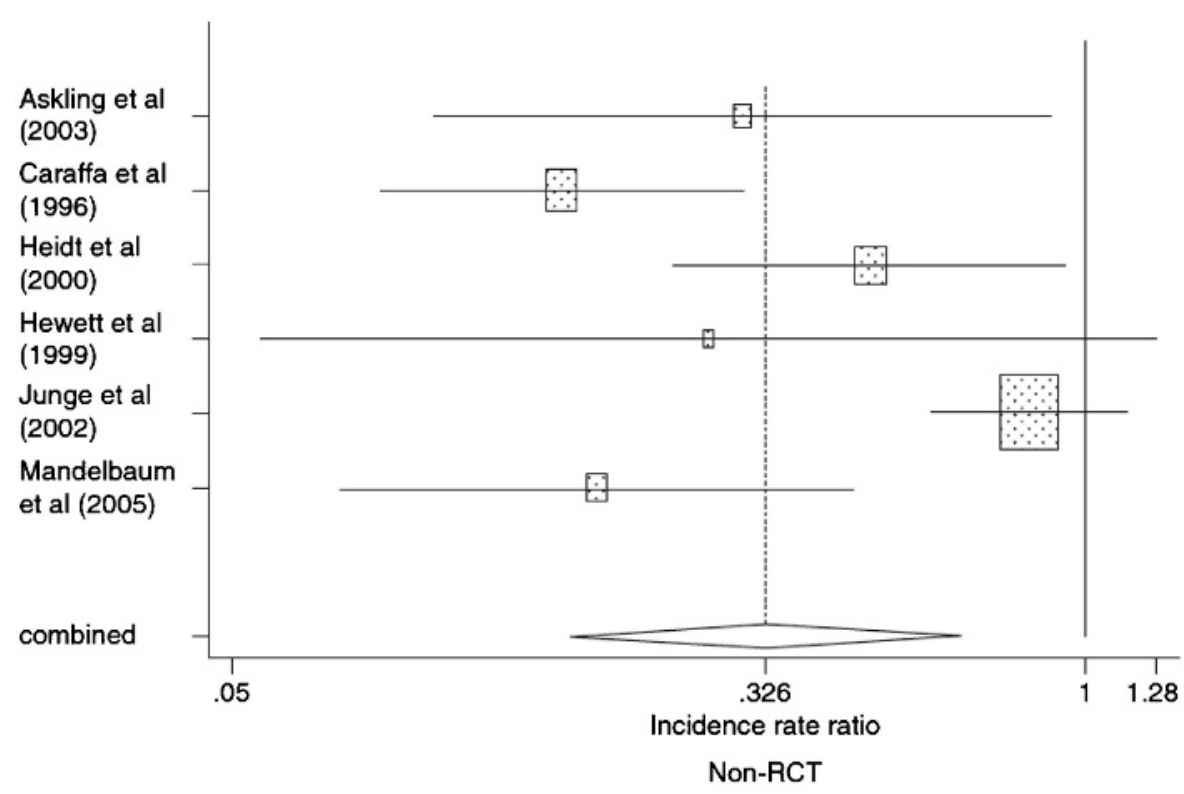

Figure 3 Non-randomised controlled trials (RCTs) examining lower-extremity neuromuscular injury-prevention strategies in soccer (reproduced with permission from Emery ${ }^{51}$ ).

\section{Outcome measurements}

In injury prevention research in youth sport, the primary outcome measurement is typically sport injury. The injury definition requires clear operationalisation including time to follow-up. Various study tools and methodologies are implemented to collect outcome measure data. Goldberg et $a^{57}$ provide a comprehensive review of the literature highlighting key epidemiological considerations in the sport injury surveillance literature in youth, examining how studies address these issues and provide recommendations for interpretation. The authors highlight three key methodological issues for consideration including: (1) the injury definition, (2) the denominator with which injuries are reported and (3) the method of data collection. They highlight that the injury definition should be clearly and operationally defined. Ideally, as more sport-specific consensus agreements are published examining definitions and methods in injury prevention research, comparisons between studies will become more feasible. Examples of such critical consensus statements have been developed for rugby union and soccer. ${ }^{58} 59$ Goldberg et $a l^{57}$ recommend provision of multiple denominators in analysing injury surveillance data (ie, injuries per athlete or per 100 athletes vs injuries per 1000 exposures or exposure hours), in order to provide the greatest perspective in examining risk within a sport, between sports and in the context of public health significance. In examining risk factors or prevention strategies, it is clearly advantageous to consider exposure to risk (ie, no of injuries/1000 exposure hours) if these denominator data are available. The method of data collection is clearly integral to the interpretation of results and comparisons between studies. Validation and examination of the reliability of all study exposure and outcome measures are critical. Strategies to minimise missing or invalid data may include validation of all study tools, adequate training and standardisation of data collection and data entry procedures, monitoring of data quality and data entry, and random data audits by an external data-monitoring committee. ${ }^{32}$ In injury-prevention research, validation of the injury-surveillance system implemented is of utmost consideration. ${ }^{60}$ An injury-surveillance system must be adapted and validated in youth and sportspecific populations. ${ }^{61}$ Blinding evaluators to study- group allocation will minimise any measurement bias.

\section{Analysis}

The scientific rigour used in the selection and utilisation of statistical analysis techniques is critical to avoid reporting misleading results. Ideally, an interdisciplinary research team will include a biostatistician in the design phase through to the final analysis and reporting stages. Friedman et $a^{\beta 2}$ provide detailed suggestions for the analysis of data from RCTs with a diversity of outcome measure types (ie, dichotomous, continuous, repeated measures, clustering, time to event, count). These statistical methods may also apply to non-RCT studies examining interventions in youth sport. Other useful analysis techniques are detailed in several statistics and biostatistics textbooks and other biostatistical literature. ${ }^{62-65}$

Incidence rate ratios (IRR) or odds ratios (OR) (with 95\% CIs) are ideally used to describe an effect estimate associated with an intervention when comparing study groups in the sport-injuryprevention literature. Hypothesis testing is not sufficient to describe the magnitude of effect or the precision of the effect estimate, which are key elements necessary to inform practice and policy. Stratification and/or multivariate analyses should be used to adjust for any baseline covariate imbalances (ie, potential confounding) as well as to examine effect modification (ie, varying level of effect based on the level of another covariate). $^{32}$ Multiple outcomes and interim analyses also have considerable sample-size implications. An intention-totreat analysis is an important consideration, though a reduction in power may relate to non-adherence and/or contamination. ${ }^{32}$ Minimising withdrawals from any study is also critical to maximising the power of a study. Missing data should also be considered in the planning stages. Techniques for imputation of missing data at the analysis stage may include "last observation carried forward, " expectation maximisation algorithm, bootstrapping and multiple imputation, and are detailed elsewhere. ${ }^{326566}$ Based on Meeuwisse et al' $\mathrm{s}^{21}$ dynamic recursive model, baseline covariates may change throughout the study follow-up period. As such, analysis strategies must be selected that will allow for the inclusion of time-dependent covariates (eg, generalised estimating equations or generalised linear mixed models). ${ }^{67}$

Cluster designs should be the design of choice in evaluating injury-prevention strategies in youth sport where participants function in the context of a cluster (eg, team, school). ${ }^{5155}$ Despite the recent attention to appropriate cluster design and analysis, there are very few intervention studies in the field of injury prevention in sport which address clustering appropriately in the design and analysis. ${ }^{3} 561118$ The "CONSORT Statement: Extension to cluster randomisation trials" in the reporting of such study results is ignored in many studies in the field of injury prevention in sport. ${ }^{56}$ Inappropriate individual-level analysis and poor reporting of cluster RCTs and cluster non-RCTs will lead to misleading study results, conclusions, practice and policy recommendations. ${ }^{55}$ Detailed 


\section{What is already known on the topic}

- There is an increasing body of evidence in the literature that examines the public health impact and risk factors for injury in youth sport.

- A model for a scientific approach to research in injury prevention in sport has been developed but has not been a significant focus to date in injury prevention in youth sport.

- The evidence for injury prevention based on the evaluation of prevention strategies in youth sport is emerging, but a minimal focus to date has been placed on the methodological approach to research design, measurement and analysis.

\section{What this paper adds}

- This paper advocates for a scientific approach to research in injury prevention in child and adolescent sport with an increasing need to focus on evaluation research.

- Methodological considerations are highlighted that are necessary to provide scientific evidence to inform practice and policy in injury prevention most appropriately in youth sport.

implications and considerations for design and analysis of cluster-RCTs and cluster non-RCTs in injury prevention are detailed elsewhere. ${ }^{5155}$

\section{CONCLUSION AND FURTHER RESEARCH}

The public health impact of injury in youth sport is great. Injury prevention is becoming a greater public health priority in light of the long-term health impact and societal burden related to decreased levels of participation in physical activity and early osteoarthritis following many injuries in youth sport. Clinical, community and policy decisions should be informed by scientific evidence in the field of injury prevention in youth sport. As a producer or user of this evidence, it is critical that we understand the methodological implications and resulting interpretations of the research in this field. Rigorous methodological approaches have long been recognised in other fields of medicine and should be a priority in research in injury prevention in youth sport. Researchers in this field should not only be leaders in injury prevention but also rigorous in their approach to research methodologies that will enable us to inform practice and policy most appropriately and most accurately.

\section{Acknowledgements: $J$ Kang is acknowledged for providing biostatistical support in the meta-analysis portion of this paper.}

Funding: CAE is funded by a Population Health Investigator Award from the Alberta Heritage Foundation for Medical Research, a New Investigator Award from the Canadian Institutes of Health Research and a Professorship in Pediatric Rehabilitation, Alberta Children's Hospital Foundation.
Provenance and peer review: Commissioned; externally peer reviewed.

Br J Sports Med 2010;44:64-69.

doi:10.1136/bjsm.2009.068353

\section{REFERENCES}

1. Cameron C, Wolfe R, Craig CL. Physical activity and sport: encouraging children to be active. Ottawa: Canadian Fitness and Lifestyle Institute, 2007.

2. Emery CA, Meeuwisse WH, McAllister JR. A survey of sport participation, sport injury and sport safety practices in adolescents. Clin J Sport Med 2006;16:20-6.

3. Emery CA. Injury prevention and future research. In: Caine DJ, Maffulli N, eds. Epidemiology of pediatric sports injuries: individual sports. Basel, Switzerland: Karger, 2005:179-200.

4. King MA, Pickett W, King AJC. Injury in Canadian youth: a secondary analysis of the 1993-94 health behaviour in school-aged children survey. Can J Public Health 1998;89:397-401.

5. Mummery WK, Spence JC, Vincenten JA, et al. A descriptive epidemiology of sport and recreation injuries in a population-based sample: results from the Alberta Sport and Recreation Injury Survey (ASRIS). Can J Public Health 1998;89:53-6.

6. Bijur $\mathbf{P}$, Trumble A, Harel $Y$, et al. Sports and recreation injuries in US children and adolescents. Arch Pediatr Adolesc Med 1995;149:1009-16.

7. Emery CA, Tyreman H. Sport participation, sport injury, risk factors and sport safety practices in Calgary and area junior high schools. Paediatr Child Health 2009;14:439-44.

8. Sleet DA, Bryn S. Injury prevention for children and youth. Am J Health Educ 2003;34:3-4S.

9. Tremblay GC, Peterson L. Prevention of childhood injury: clinical and public policy challenges. Clin Psychol Rev 1999;19:415-34.

10. Rimsza M, Schackner R, Bowen K, et al. Can child deaths be prevented? The Arizona child fatality review program experience. Pediatrics 2002;110:1-7.

11. Gordon JE. The epidmiology of accidents. Am J Public Health 1949;39:504-15.

12. Gibson JJ. The contribution of experimental psychology to the formulation of the problem of safety — a brief for basic research. In: Behavioral approaches to accident research. New York: Association for the Aid of Crippled Children, 1961:77-89.
13. Haddon W Jr. A logical framework for categorizing highway safety phenomena and activity. J Trauma 1972;12:193-207

14. Runyan CW. Using the Haddon matrix: introducing the third dimension. Inj Prev 1998:4:302-7.

15. Morrongiello BA. The role of supervision in childinjury risk: Assumptions, issues, findings, and future directions. J Pediatr Psychol 2005;30.

16. Schwebel D. Barton B. Contributions of multiple risk factors to child injury. J Pediatr Psychol 2005;30:553-61.

17. van Mechelen W, Hlobil $H$, Kemper HC. Incidence, severity, aetiology and prevention of sports injuries. A review of concepts. Sports Med 1992;14:82-99.

18. Finch C. A new framework for research leading to injury prevention. J Sci Med Sport 2006;9:3-9.

19. Meeuwisse W. Assessing causation in sport injury: A multifactorial model. Clin J Sport Med 1994:4:166-70.

20. Bahr R, Krosshaug T. Understanding injury mechanisms: a key component of preventing injuries in sport. Br J Sports Med 2005;39:324-9.

21. Meeuwisse WH, Hagel BE, Emery CE, et al. A dynamic model of etiology in sport injury: the recursive nature of risk and causation. Clin J Sport Med 2007:17:215-19.

22. Gissane C, White J, Kerr K, et al. An operationa model to investigate contact sports injuries. Med Sci Sports Exerc 2001:33:1999-2003.

23. Pless B. Surveillance alone is not the answer. Inj Prev 2008:14:220-2

24. Last JM. A dictionary of epidemiology. 4th edn. Ottawa: IEA, 2001:155

25. Robertson LS. Injury epidemiology. New York: Oxford University Press, 1992

26. Finch C. Suveillance is necessary but not sufficient for prevention. Inj Prev 2008;14:415.

27. Emery, CA. Risk factors for injury in child and adolescent sport: a systematic review of the literature. Clin J Sport Med 2003;13:256-68.

28. Emery CA, Meeuwisse WH. The effectiveness of neuromuscular training program to reduce injuries in youth soccer. A cluster-randomized controlled trial. Br J Sport Med 2008:42:497.

29. Emery CA, Meeuwisse WH, McAllister JR. A prevention strategy to reduce the incidence of injury in high school basketball: A cluster randomized controlled trial. Clin J Sport Med 2006;16:182.

30. Emery CA, Cassidy JD, Klassen $T$, et al. The effectiveness of a proprioceptive balance training program in healthy adolescents. A cluster randomized controlled trial. CMAJ 2005;172:749-54.

31. Portney LG, Watkins MP. Foundations of clinical research; applications to practice. 3rd edn. Upper Saddle River: Prentice Hall, 2007.

32. Friedman LM, Furberg CD, DeMets DL. Fundamentals of clinical trials. 3rd edn. New York: Springer, 1998.

33. Richmond S, Emery CA, Doyle-Baker T, et al. The implementation and baseline data of a combined sport injury and obesity prevention program in junior high school. Clin J Sport Med 2009;19:250.

34. McGuine TA, Keene JS. The effect of a balance training program on the risk of ankle sprains in high school athletes. Am J Sports Med 2006:34:1103-11.

35. Soligard T, Myklebust G, Steffen K, et al. Comprehensive warm-up programme to prevent injuries in young female footballers: cluster randomized controlled trial. BMJ 2008;337:a2469.

36. Steffen K. (2008) Introduction.In: Injuries in female youth football. Prevention performance and risk factors [dissertation]. Norwegian School of Sport Sciences, Oslo Sport Trauma Research Centre, Oslo.

37. Olsen $\mathbf{0 E}$, Myklebust G, Engebretsen L, et al. Exercises to prevent lower limb injuries in youth sports: cluster randomised controlled trial. BMJ 2005; 330:449

38. Wedderkopp M, Kaltoft M, Holm R, et al Comparison of two intervention programmes in young female players in European handball—with and without ankle disc. Scand J Med Sci Sports 2003:13:371-5 
39. Wedderkopp M, Kaltoft M, Lundgaard B, et al. Prevention of injuries in young female players in European team handball. A prospective intervention study. Scand J Med Sci Sports 1999:9:41-7.

40. Mickel TJ, Bottoni CR, Tsuji G, et al. Prophylactic bracing versus taping for the prevention of ankle sprains in high school athletes: a prospective, randomized trial. J Foot Ankle Surg 2006;45:360-5.

41. McIntosh AS, McCrory P. Effectiveness of headgear in a pilot study of under 15 rugby union football. Br J Sports Med 2001;35:167-9.

42. Caine D, Maffulli N, Caine C. Epidemiology of injury in child and adolescent sports; Injury rates, risk factors and prevention. Clin Sports Med 2008;27:19-50.

43. Heidt RS Jr, Sweeterman LM, Carlonas RL, et al. Avoidance of soccer injuries with preseason conditioning. Am J Sports Med 2000;28:659-62.

44. Mandelbaum BR, Silvers HJ, Watanabe DS, et al. Efectivness of neuromuscular and proprioceptive training program in preventing anterior cruciate ligament injuries in female athletes: 2-year follow-up. Am J Sport Med 2005;33:1003-10.

45. Caraffa A, Cerulli G, Projetti M, et al. Prevention of anterior cruciate ligament injuries in soccer. A prospective controlled study of proprioceptive training Knee Surg Sports Traumatol Arthrosc 1996:4:19-21.

46. Hewett TE, Lindenfeld TN, Riccobene JV, et al. The effect of neuromuscular training on the incidence of knee injury in female athletes. Am J Sports Med 1999;27:699-705.

47. Junge A, Rosch D, Peterson L, et al. Prevention of soccer injuries: a prospective intervention study in youth amateur players. Am J Sports Med 2000:30:652-9.
48. Engebretsen AH, Myklebust G, Holme I, et al. Prevention of injuries among male soccer players: a prospective, randomized intervention study targeting players with previous injuries or reduced function. Am J Sports Med 2008;36:1052-60.

49. Soderman K, Werner S, Pietila T, et al. balance board training: prevention of traumatic injuries of the lower extremity in female soccer players? A prospective randomized intervention study. Knee Surg Sports Traumatol Arthrosc 2000:8:356-63.

50. Askling C, Karlsson J, Thorstensson A. Hamstring injury occurrence in elite soccer players after preseason strength training with eccentric overload. Scand J Med Sci Sports 2003;13:244-50.

51. Emery CA. Types of evaluation studies in research methods in sport medicine. In: Vergahen $\mathrm{E}$, van Mechelen W, eds. Sports injury research. London: Oxford University Press, 2009:167-80.

52. Deeks JJ, Altman DG, Bradburn MJ. Statistica methods for examining heterogeneity and combining results from several studies in meta-analysis. In: Egger M, Smith GD, Altman DG, eds. Systematic reviews in health care: meta-analysis in context. London: BMJ Publishing Group, 2001.

53. Statacorp. Stata statistical software: release 10.0 College Station: Stata Corporation, 2007.

54. Donner A, Klar N. Design and analysis of cluster randomization trials in health research. New York: Oxford University Press, 2000.

55. Emery CA. Considering cluster analysis in sport medicine and injury prevention research. Clin J Sport Med 2007:17:211-14.

56. Moher D, Schulz KF, Altman D. CONSORT Statement: Revised recommendations for improving the quality of reports of parallel-group randomized trials. JAMA 2001;285:1987-91.

57. Goldberg AS, Moroz L, Smith A, et al. Injury surveillance in young athletes. Sport Med 2007;37:265-78.

58. Fuller CW, Molloy MGM, Bagate C, et al. Consensus statement on injury definitions and data collection procedures for studies of injuries in rugby union. Clin J Sport Med 2007:17:177-81

59. Fuller CW, Ekstrand J, Junge A, et al. Consensus statement on injury definitions and data collection procedures in studies of football (soccer) injuries. Br J Sports Med 2006;40:193-201.

60. Meeuwisse W, Love E. Athletic injury reporting: development of universal systems. Sport Med 1997:24:184-204.

61. Emery CA, Meeuwisse WH, Hartmann S. Risk factors for injury in adolescent soccer. Pilot implementation and validation of an injury surveillance system. Am J Sport Med 2005;33:1882-91.

62. Norman GR, Streiner DL. Biostatistics: the bare essentials (2nd edn). Toronto: Decker, 2001.

63. Altman DG. Practical statistics for medical research London: Chapman \& Hall, 1991.

64. Rosner BA. Fundamentals of biostatistics. 6th edn. Boston: Duxbury Press, 2006

65. Dempster AP, Laird NM, Rubin DB. Maximum likelihood from incomplete data via the EM algorithm J Roy Stat Soc Series B (Methodological) 1977;39:1-38.

66. Little RJA, Rubin DB. Statistical analysis with missing data. New York: Wiley, 1987.

67. Liang KY, Zeger SL. Longitudinal data analysis using generalized linear models. Biometrika 1986;73:13-22. 